\title{
Preliminary Study on Pollution Isolation of Civil Air Defence Underground Engineering
}

\author{
Ji Y unzhe ${ }^{1}$, Wang Xiaojie ${ }^{1 *}$, Li Jintian ${ }^{1}$ \\ ${ }^{1}$ Naval Logistics A cademy, 300450 Tianjin, China
}

\begin{abstract}
In order to control the airborne spread of pollutants in civil air defences underground projects, the pollution source rooms are isolated. In this paper, CFD simulation technology is used to compare the effect of different positions of air supply and exhaust outlets on the removal of contaminants in the polluted isolation room. Pressure difference control is proposed to prevent the diffusion of polluted air from the isolation room to the clean area, and the realization of pressure difference control under emergency ventilation mode is discussed.
\end{abstract}

\section{Introduction}

When there is a certain kind of room in the civil air defence underground engineering, the pollution source in the room continuously releases pollutants into the air and diffuses with the air, for example, there are materials and equipment continuously releasing harmful gases in the room, or there are infectious disease patients in the room, who release pathogenic bacteria transmitted with the air, so this kind of room is used for isolation and is the polluted area of the civil air defence underground engineering. While this kind of pollutant itself is gas or fatal infectious bacteria spread with the air, causing personnel poisoning or infection, and underground space is more closed than ground buildings, no external doors and windows, only through its exit to communicate with the outside, most civil air defence underground projects adopt mechanical ventilation and air conditioning to maintain the air environment in the project. In this relatively closed project, pollutants are difficult to discharge directly from the polluted area through natural ventilation, and the polluted air is easy to flows from the polluted area into other areas of the project. Therefore, it is necessary to isolate such polluted areas from the clean areas in the project, that is, the rooms with pollution sources are set as isolated areas. This paper discusses, in the civil air defence underground engineering, how to use the ventilation and air conditioning system to effectively remove the pollutants released from the polluted isolation room and how to form pressure difference control to isolate and prevent the air in the polluted area from the clean area, especially under the emergency ventilation mode.

\section{Discharge the pollutants of contami- nated area}

The positions of air supply and exhaust outlets should be reasonably designed indoors, and the number of air changes should be reasonable, so as to form an effective air distribution and discharge the pollutants released in the room in time.

\subsection{Influence of inlet and outlet position}

Use CFD to simulate the airflow organization of the polluted room, as shown in Fig.1 to Fig.4. Different positions of the air supply outlet and the air return outlet produce different air distribution. The position of point $A$ in the figure is the release point of the pollution source. Fig. 1 and Fig.2 show the roof air supply (red), and Fig.1 shows sidewall air return exhaust (green). In Fig.2, in addition to the sidewall air exhaust, an air exhaust is added at bedside near the pollution source. Fig. 3 shows the same air exhaust as Fig.1, and the air supply is on the opposite wall of the air exhaust. Fig. 4 shows the same air exhaust as Fig.2b) is a streamline diagram, which can show the air flow organization in the room.

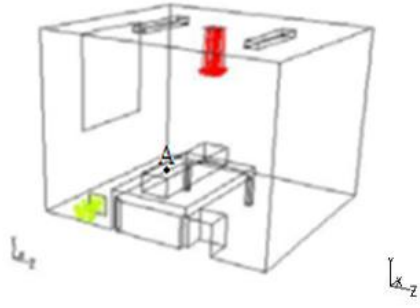

a ) inlet and outlet location

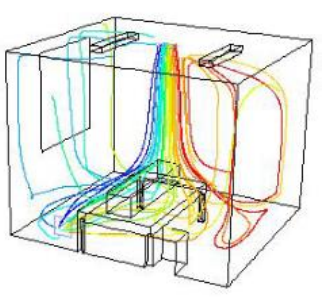

b ) streamline
Fig.1 Roof supply and sidewall exhaust

\footnotetext{
* Corresponding author: 13174801521@ 163.com
} 


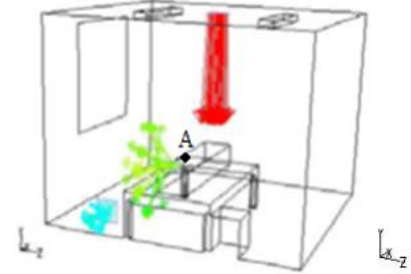

a) inlet and outlet location

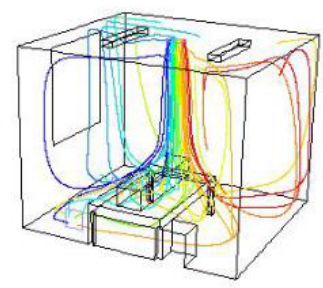

b) streamline
Fig.2 Roof supply and sidewall exhaust + bedside exhaust

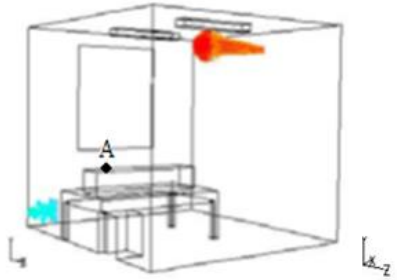

a) inlet and outlet location

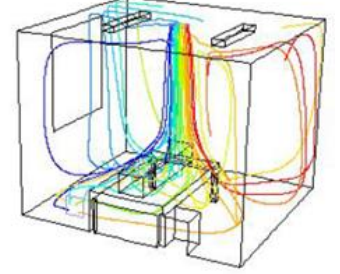

b) streamline
Fig.3 Sidewall supply and sidewall exhaust

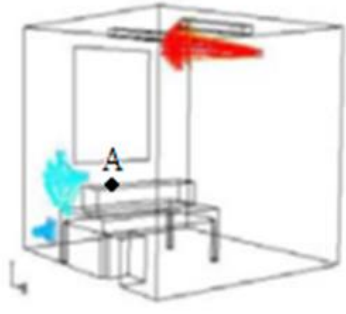

a) inlet and outlet location

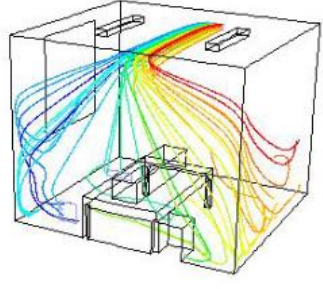

b) streamline
Fig.4 Sidewall supply and sidewall return +bedside return

By comparing Fig. 1 and Fig.2, it can be known that when the inlets supply air at the top, as shown in Fig. 1b), the pollutants are entrained into the air supply airflow, and flow between the inlet and the outlet along with the air flow, and the pollutants are diffused, and finally flow to the outlets, as shown in Fig.2, the outlet is added to bedside near the pollution source, and the pollutants are directly discharged from the exhaust outlet, as shown as Fig.2b), so it is beneficial to timely discharge of pollutant before diffusion.

In Fig. 3 and Fig.4, the position of the inlet is changed to the wall opposite to the outlet, the air is supplied from the side, and the air supply inlet is far away from the pollution source. As can be seen from Fig. 3b), since the pollution source is in the eddy current, the pollutants are diffused, and it is difficult to flow into the air exhaust outlet. Even if the air exhaust outlet is added near the pollution source as shown in fig. $4 \mathrm{~b}$ ), there is no obvious improvement. Because the airflow velocity in the recirculation zone is low, it is easy to cause the deposition of pollutants in this area, which is not easy to remove.

From the above analysis, the reasonable position of air supply and exhaust, especially the position of air supply outlet, to form a reasonable air distribution, is the key to improve the efficiency of pollution discharge. The arrangement of the inlet shall avoid the pollution source from being located in the eddy current of the indoor air distribution, which is not conducive to the discharge of pollutants, and at the same time, it shall also avoid the pollutants from being directly located in the direct flow area of the supply air flow, because this will lead to the further diffusion of pollutants in the room with the supply air flow; An air outlet is added near that pollution source to facilitate the discharge of pollutants.

\subsection{Air changes number}

As the air inlet and outlet of the pollution isolation room are usually arranged, it is difficult to form unidirectional flow and the pollutant discharge method belongs to dilution control, so the number of air changes directly affects the effect of sewage discharge. Therefore, the number of air changes should not be too small, the lower limit is $6 \mathrm{ACH}$, but if the air changes too much, it will cause excessive disorder of indoor air flow and pollutant diffusion which make pollutant difficult to concentrate. So the upper limit is $15 \mathrm{ACH}$.[1]

\section{Differential pressure isolation control}

Isolation area cannot be completely closed, there are gaps between doors and windows. In order to prevent polluted air from flowing out of the polluted area through the gaps, the pressure difference control should be adopted, the isolation area should maintain a pressure relatively lower than that of the surrounding area, that is, relative negative pressure, so as to ensure that airflow flows into the polluted isolation area from the surrounding area, which prevent the expansion of polluted air from isolation area.

\subsection{Pressure difference settings}

The pressure difference is generally realized by the difference between the supply air volume and the exhaust air volume of the room: the supply air volume of the pollution isolation area is lower than the exhaust air volume, and the difference of the air volume is made up by the infiltration air quantity of the room door and window gap. The infiltration air encounters resistance through the cracks of doors and windows, resulting in pressure drop and realizing the pressure difference between inside and outside the room. Therefore, the value of the pressure difference is determined by the infiltration air volume and the geometric characteristics of the door and window gap.

The calculation formula of the air infiltration rate of the door and window gap in the 《Practical Heating and Air Conditioning Design Manual 》 is as follows:

$$
L=a \triangle P b
$$

Where L--Reference infiltration air volume per meter of door and window gap, $\mathrm{m} 3 /(\mathrm{h} \cdot \mathrm{m})$;

a,b--The characteristic constant and exponent related to the structure of doors and windows, $\mathrm{b}$ is between 0.56 and $0.78 ;[2]$ 
$\Delta \mathrm{P}$ - Indoor and outdoor pressure difference, $\mathrm{Pa}$

The pressure difference value is closely related to the sealing degree of doors and windows in the room. The sealing performance of doors and windows is good, and only a small amount of infiltration air is needed for the same pressure difference value, so improving the sealing performance of doors and windows is an effective guarantee for achieving safe isolation.

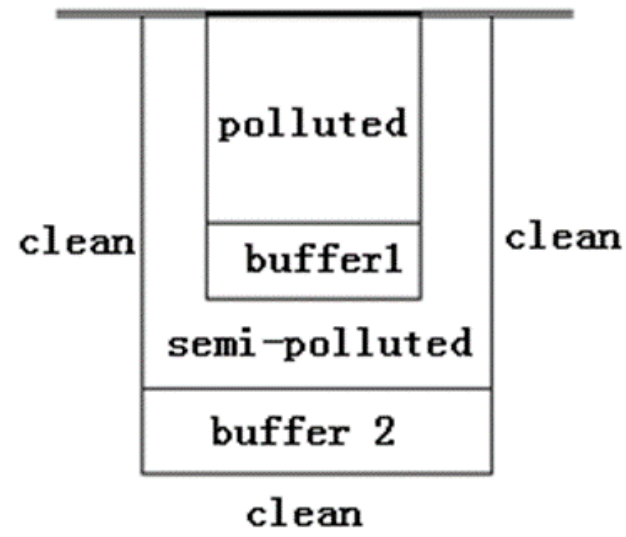

Fig.5 Schematic diagram of layout of zone 3 and buffer 2

In order to realize isolation more safely, "three zones and two buffers" are usually adopted: polluted zone, semi-polluted zone and clean zone, and two buffer zones between them as shown in Figure 5. The polluted zone is the area where the pollution source is located, the semipolluted zone is generally the working area of the staff who are in contact with the pollution source, and the clean zone is the living and resting area of the staff, or other areas unrelated to the pollution source. The door should be set on the wall of the buffer zone. Buffer zones are arranged between different zones. the pressure of each zone is designed according to the pressure difference gradient, for example, the polluted zone is $30 \mathrm{~Pa}$, the buffer zone 1 is $-15 \mathrm{~Pa}$, the semi-polluted zone is $-10 \mathrm{~Pa}$, the buffer zone 2 is $-5 \mathrm{~Pa}$, and the clean zone is $0 \mathrm{~Pa}$. According to the pressure gradient, air flows from the clean zone to the buffer zone 2 to the semi-polluted zone to the buffer zone 1 to the polluted zone, which ensure that air from the contaminated area does not leak to other areas. [3] At present, the difference between internal pressure and external pressure is not specified in the standard, which should be determined according to the risk degree of the polluted area. There are many studies on the isolation ward of airborne diseases, and the pressure gradient varies from 2 to $10 \mathrm{~Pa}$.

\subsection{Setting of air supply and exhaust}

In order to prevent cross infection, the air supply system and exhaust system of the pollution isolation area shall be separated from the air supply system and exhaust system of other areas in the civil air defence underground works. The air in the polluted area shall be directly discharged to the outside of the project after necessary disinfection and filtration, and the exhaust outlet shall be far away from the normal inlet and outlet of the civil air defence underground project. A separate exhaust fan shall be set at the end of the pollutant exhaust system, and the air volume and pressure shall meet the requirements to ensure the negative pressure of the whole exhaust part and prevent the leakage of pollutants caused by local positive pressure. When it is difficult to treat the harmful substances in the air discharged from the pollution isolation area, the return air is usually not used, and the new fan is directly set to supply air. [4]

The air supply volume which is constant is determined to meet the health requirement of the room. Generally, a constant air volume control valve can be set at the air supply inlet. The exhaust air volume is to maintain the control of pressure difference. As the relationship between differential pressure and exhaust air volume is affected by the geometric characteristics of doors and windows as well as the design calculation, the actual operating differential pressure may deviate from the design value to a certain extent. A constant differential pressure control valve shall be set at the exhaust outlet and interlocked with the frequency conversion exhaust fan to regulate the exhaust air volume, to ensure that the differential pressure value of the room is within the allowable range.

Check valves shall be installed at all inlets and outlets in the isolation area to prevent cross air flow and mutual pollution.

\section{Pressure control ventilation mode in case of emergency}

In ordinary buildings, the air quality of the external environment is safe and reliable. So, the pressure of the clean area is set to slightly positive pressure and the pressure of the pollution isolation area is set to negative pressure, and the air quality directly infiltrated from the outside world is safe. But the civil air defence underground project undertakes the protection task under the emergency, when the outside air is polluted and people take shelter in the protection project, the project should enter the isolation ventilation mode or the filtration ventilation mode.

\subsection{Isolated ventilation mode}

When the outside of the project is suddenly polluted and the composition and concentration of pollutants are difficult to determine, the project should enter the isolation ventilation mode. When the isolation ventilation mode is adopted, the doors on the exit of the project and all the valves of the air supply and exhaust system are closed, so the project is isolated and protected, and the air only circulates internally. If the air supply and exhaust of the polluted area stops at this time, the concentration of pollutants in the polluted area will rise, and the pressure gradient between the polluted area and the clean area cannot be guaranteed, the polluted air in the contaminated area may penetrate the clean area. If the air exhaust unit in the polluted area is turned on, the infiltration airflow will flow from the clean area to the polluted area, causing the pressure in the clean area to 
drop and the outside contaminated air to infiltrate. In order to ensure that the clean area is not polluted by external contaminated air and internal contaminated air, it is necessary to maintain the normal pressure of the clean area while establishing the negative pressure of the contaminated area.

1) When the air supply system stops running, an isolation exhaust fan is independently arranged for that polluted area, and the air volume of the exhaust fan is the infiltration air volume required for maintaining the pressure difference between the pollute area and the adjacent area;

2) Compressed air bottles or air storage tanks are arranged in the buffer zone to release clean air and supplement the air volume infiltrating into the polluted area. Cancel the pressure difference between the buffer zone and the clean zone to avoid the inflow of air in the clean zone, resulting in the pressure of clean zone drop. A more reliable way is to isolate a small closed space on the side of the clean area outside the isolation door, and pressurize it through a compressed gas cylinder or a gas storage tank to ensure that the air in the clean area does not infiltrate and no polluted air seeps out.[5]

\subsection{Filtrate ventilation mode}

When the pollutants of the outside of the project is stable and can be treated, the project should enter the filtration ventilation mode.

When the filtration ventilation mode is adopted, the air entering the project shall be subjected to dust removal and gas filtration treatment, and the overpressure exhaust system shall be adopted for air exhaust. The interior of the project shall be overpressure as required to prevent the infiltration of external air. In the filtering ventilation mode, the supply blower works and the exhaust blower stops working. When the internal pressure of the project rises to the required overpressure, the automatic exhaust valve at the project exit is opened, and the air is exhausted through the air exhaust system at the exit for overpressure exhaust. In the relevant design specifications, under the filtration ventilation mode, the interior of the project should be a positive pressure area, maintaining a positive pressure of 30-100Pa.

When there is a polluted area inside the civil air defence underground project, the air inside the polluted area should be prevented from infiltrating into the clean area, and at the same time, the outside contaminated air caused by the low pressure of the polluted area should also be prevented from infiltrating into the polluted area. Therefore, the pressure of the polluted area inside the project should be lower than that of the clean area inside and higher than that of the external environment. The pressure difference gradient existing in the project should be set as: The polluted area shall maintain a lower positive pressure of $30 \mathrm{~Pa}$. The pressure of buffer zone 1 , semi-polluted zone, buffer zone 3 and clean zone shall increase gradient. The pressure of clean zone shall be maintained above $60 \mathrm{~Pa}$.
In view of the particularity of underground civil air defence projects, if there are pollution sources releasing airborne pollutants in the projects, special pollution isolation zones should be set up.

1)Reasonably arranging air inlets and outlets and air exchange times in the isolation area to form an air distribution for effective pollution discharge;

2)An effective directional airflow is formed through the structural arrangement and the pressure gradient of 'three zones and two buffers' to prevent pollutants from diffusing to a clean zone;

3) Under isolating ventilation mode, the negative pressure of the polluted area should be maintained, and the non-negative pressure of the clean area should also be ensured;

4) Under filtration ventilation mode, the negative pressure of the polluted area relative to the clean area and the positive pressure relative to the outside should be ensured.

In this paper, that method of isolating the pollute area in the underground civil air defence project is preliminarily considered, and there are still many practical problems to be discussed and study, such as how to combine the ventilation system of the pollute isolation area with the ventilation system of the project, and how to convert the ventilation systems of the isolation area under different ventilation modes.

\section{References}

1. Di Y anqiang, Wang Qingqin and Zhao Li Testing Study and Numerical Simulation of Air Distribution for Infectious Isolation Ward, Journal of Refrigeration and Heating , 2005,9

2. Zhang Zhigang, YE Jin-hua and LI Zeng Comparison btween Comprehensive Correction Factors of Cold Air Infiltration, Journal of refrigeration air condition \& electric power machinery,2006,27(3)

3. $\mathrm{Hu}$ Jihui The analysis and design foe negative pressure isolation wards Fujian Architecture Construction 2011.1

4. Liu Junjie, Wang Bin, Zhao Xinzhi el Issues in pressure control of negative pressure isolation Wards Journal of HV \& AC 2006.5

5. Gen Shibin,W ang Ruihai Discussion on Overpressure Problem of Protective 2004 Engineering Council and Academic Meeting of Protective Engineering Branch of CCES 996-971

\section{Conclusion}

